\title{
Research on Profit Distribution Between Dairy Farmers and Manufacturing Enterprises in Dairy Supply Chain Based on Qualified Rate
}

\author{
Teng Fei, Cuixia Li* \\ School of economics and management, Northeast Agricultural University, Harbin 150030, Heilongjiang, \\ China \\ *Corresponding Author.
}

\begin{abstract}
As an indispensable industry for the health and prosperity of the Chinese nation, dairy industry is a symbolic industry of agricultural modernization and a strategic industry of coordinated development of primary, secondary and tertiary industries. With the rapid development of China's dairy industry, China's dairy product quality and safety risks still exist. The imbalance of profit distribution is one of the important reasons for the confusion of dairy market and quality and safety problems. The essence of the normal operation of the dairy supply chain and the guarantee of the quality and safety of dairy products lies in the correct handling and coordination of the interest relationship between the enterprises in each node of the supply chain. Reasonable benefit coordination mechanism and fair benefit distribution mode are of great significance to ensure the quality and safety of dairy products, maintain the stable relationship of dairy supply chain, and promote the healthy and sustainable development of China's dairy industry. This paper discusses the optimal quality and safety level and optimal revenue of two-stage dairy supply chain based on the pass rate of dairy farmers and dairy processing enterprises under decentralized and centralized decision-making. In order to improve the quality efforts of dairy farmers, the internal and external loss sharing contract is designed, that is, dairy farmers and dairy processing enterprises share consumer losses, while manufacturing enterprises provide certain quality cost subsidies for dairy farmers. Finally, through the example analysis, it is verified that the benefit sharing and risk sharing between dairy farmers and national processing enterprises can be realized through the contract. Through contract coordination, the profit distribution of dairy farmers and processing enterprises and the quality and safety level of supply chain were optimized, and the importance of quality control in raw milk production was further verified.
\end{abstract}

Keywords: Dairy products, supply chain, Dairy farmers, Manufacturing enterprises, Distribution of interests

\section{Introduction}

The quality and safety of dairy products are closely related to the interests of the main body of the dairy supply chain. The unbalanced interest relationship will lead to the imbalance of the supply chain. The weak side has no production enthusiasm, and even risks damaging the quality and safety of dairy products, in order to maximize their own interests. The strong side will intensify the risk transfer and form a vicious circle, which will lead to the low quality and safety level of the whole supply chain. Using reasonable profit distribution method, encourage stakeholders in the supply chain to work hard for quality and safety. CRU milk production and dairy products processing are the main links affecting the quality and safety of dairy products. In this paper, the two echelon supply chain of dairy enterprises and dairy processors is taken as the research object. The influence of qualified rate and unqualified rate is considered, and the optimal income level and optimal quality level under centralized decision and decentralized decision are analyzed respectively. Aiming at the optimal income level and optimal quality level under centralized decision, an internal and external loss sharing contract is proposed. In order to distribute the interests of both sides, encourage both sides to improve the level of quality work, and achieve the goal of ensuring and improving the quality and safety of dairy products.

ISSN: 0010-8189

(C) CONVERTER 2020

607

www.converter-magazine.info 


\section{Analysis of Quality and Safety Benefits of Dairy Supply Chain}

\subsection{Classification of quality and safety of dairy products}

In the concept of quality and safety of dairy products, compliance with national requirements and standards is the minimum standard of quality and safety of dairy products, which will not damage and endanger the health of consumers, and will not cause diseases. Inspection is the basic standard for dairy products to enter the market. China has clear regulations on the minimum quality and safety of fresh milk, as shown in table 1 . The total number of colonies, aflatoxin, M1, somatic cell number, lead, sodium chloride, lithium chloride, melamine and leather hydrolysate are negative indicators, which require the highest level. Milk protein and milk fat are positive indicators of fresh quality, and the lowest content is required.

Table 1 minimum quality and safety standards of fresh milk in China

\begin{tabular}{ccc}
\hline Index classification & index & Limited standard \\
\hline Health indicators & Total number of colonies & $\leq 2$ million CFU $/ \mathrm{ml}$ \\
& Somatic cell number & $\leq 400000$ pieces $/ \mathrm{ml}$ (EU and New \\
& & Zealand) \\
& & Up to 500000 pieces $/ \mathrm{ml}$ (Canada) \\
& Up to 750000 pieces $/ \mathrm{ml}$ (US) JYC \\
Pollutant index & Aflatoxin M1 & $\leq 0.5 \mu \mathrm{g} / \mathrm{kg}$ \\
& Lead & $\leq 0.05 \mathrm{mg} / \mathrm{kg}$ \\
Health indicators & mercury & $\leq 0.01 \mathrm{mg} / \mathrm{kg}$ \\
& chromium & $\leq 0.3 \mathrm{mg} / \mathrm{kg}$ \\
mutritional indicator & Leathine & $\leq 2.5 \mathrm{mg} / \mathrm{kg}$ \\
& Milk protein & No detection \\
& Milk fat & $\geq 2.8 \mathrm{~g} / 100 \mathrm{~g}$ \\
& & $\geq 3.1 \mathrm{~g} / 100 \mathrm{~g}$ \\
\hline
\end{tabular}

On the premise of ensuring safety, dairy products are also divided into different quality grades. In view of China's food quality classification, dairy products are divided into four categories, as shown in table 2, including ordinary milk, pollution-free milk, green food milk and organic milk;

Table 2 Quality and safety level of dairy products

\begin{tabular}{llll}
\hline $\begin{array}{l}\text { Classification of dairy } \\
\text { products }\end{array}$ & characteristic & Certification system & Typical representative \\
\hline Ordinary milk & $\begin{array}{l}\text { Meet the minimum } \\
\text { standards for testing }\end{array}$ & \\
Pollution free milk & $\begin{array}{l}\text { For high toxic drugs, Pollution free food } \\
\text { there is no limit for certification } \\
\text { medium and low } \\
\text { concentration drugs. }\end{array}$ & \\
& $\begin{array}{l}\text { For high toxic drugs, } \\
\text { there is no limit for } \\
\text { medium and low } \\
\text { concentration drugs }\end{array}$ & \\
It is allowed to use a Green & food - \\
CONVERTER 2020 & & &
\end{tabular}




\begin{tabular}{|c|c|c|c|c|}
\hline & $\begin{array}{l}\text { certain amount of } \\
\text { pesticides, fertilizers, } \\
\text { hormones and other } \\
\text { synthetic substances }\end{array}$ & certification & & \\
\hline Organic milk & $\begin{array}{l}\text { It is absolutely } \\
\text { forbidden to use any } \\
\text { synthetic substances in } \\
\text { the production process }\end{array}$ & $\begin{array}{l}\text { Organic } \\
\text { certification }\end{array}$ & food & $\begin{array}{l}\text { Organic food } \\
\text { certification Jindian, } \\
\text { Guiyuan, Shengmu, etc }\end{array}$ \\
\hline
\end{tabular}

Ordinary milk belongs to the lowest level as long as it meets the national control standards and does not use prohibited substances. Milk with higher quality than ordinary milk is environmental protection milk that meets the national emission free food certification. It is produced according to five directives and one specification. High concentration and high toxicity are not allowed in the production process, but there are no strict restrictions on medium and low concentration. Green food milk is a kind of environmental protection, no environment, safety, nutrition and high quality milk, which corresponds to the national ecological food certification. In the production process, pesticides, fertilizers, hormones and other synthetic substances can be limited supply, organic milk is a kind of natural pollution-free milk in line with the national organic food certification. The use of synthetic substances in the production process is absolutely prohibited. In the above four varieties, ordinary milk only reached the safety standard, and its nutritional value was weak compared with other types of milk. Organic milk was the highest quality among the four varieties. The main differences between organic milk and ordinary milk are feed sources, feeding methods and processing technology. Packaging, storage and circulation should also meet strict ecological food standards.

\subsection{Analysis of quality and safety benefits of dairy products}

The quality and safety effect of dairy products can be divided into negative effect and positive effect. The negative effect refers to the loss of property and reputation caused by unsafe cash. To ensure the quality and safety of Guopin is closely related to the interests of enterprises. Once quality and safety problems occur, enterprises will not only be strictly inspected by the government, but also lose consumer confidence, resulting in significant reputation losses. Sanlu Group "melamine" incident is a good proof. According to statistics, more than 10000 infants and young children have been harmed by triple chlorine milk powder, resulting in four deaths. The melamine incident affected a wide range of people with extremely bad nature, and many officials were removed.

On the one hand, it took Sanlu Group, a small cooperative, 50 years to become a NUMA dairy company in 1956. After the melamine incident, China's national product industry experienced the biggest winter ever. Consumer confidence in domestic dairy products has also declined significantly. Imported milk powder seized the market opportunity, most of the dairy enterprises suffered losses. With the continuous strengthening of the government's supervision and inspection on the quality and safety of dairy products, China's dairy industry has gradually recovered. Unsafe dairy products have caused huge losses to enterprises and the whole dairy industry. Ensuring the quality and safety of dairy products is the basic premise for the healthy development of the dairy industry.

On the other hand, with the improvement of residents' consumption level and nutrition awareness, consumers' requirements for dairy products are not only safe and reliable, but also more important for the nutritional value of dairy products. Only products with improved safety and quality can be favored by consumers. According to Holstein survey data, dairy consumers pay more attention to five indicators: no artificial pigment, all natural, no artificial, non transgenic and organic flavor. Natural organic milk has become the first choice of dairy consumers.

In order to meet the needs of consumers, Mengniu, Yili, modern animal farms and other large dairy and ranching companies have established organic high-quality dairy products.High quality milk is positioned as medium and high quality milk with protein content above $3.2 \mathrm{~g} / 100 \mathrm{ml}$ and high price. The high quality common milk on the market is

ISSN: 0010-8189

(C) CONVERTER 2020

609

www.converter-magazine.info 
shown in table 3-2.High end milk has high requirements for raw milk. The content of milk protein should be more than $3.2 \%$, the total number of bacteria should be less than $100000 \mathrm{CFU} / \mathrm{ml}$, and the somatic cell count should be less than $400000 \mathrm{CFU} / \mathrm{ml}$.

2009Since, the sales volume of high-quality milk has increased rapidly, and the proportion of liquid milk has increased year by year. By 2018, the market share of high-quality milk in ordinary liquid milk has reached $24 \%$, and the second is basic white milk, with a year-on-year growth of $23 \%$, which is higher than that of other normal sub categories of liquid milk under normal temperature. The growth of demand for high-quality milk has also brought high profits to dairy enterprises, Yili dairy giant is an example. Since its release, its high-quality dairy products Jindian has continuously increased its proportion in Yili's total revenue. According to the forecast of Orient Securities Research Institute, it will reach $10.07 \%$ by 2018 , and high-quality milk has become an important value-added field for dairy enterprises.3. Problem description and basic hypothesis of profit distribution between dairy farmers and processing enterprises based on qualified rate ${ }^{[1]}$.

The quality and safety of dairy products are closely related to the interests of the main body of the dairy supply chain. It is difficult to ensure the safety and quality of dairy products through simple purchase and sale relationship. Therefore, we must find a kind of interest relationship that can motivate the main body of the supply chain to strive to ensure and improve the quality and safety of dairy products, and reasonably and fairly distribute the interests of the supply chain, so as to simplify the research work ${ }^{[2]}$. This paper only considers the double-layer supply chain composed of milk producers and milk processors, with the purpose of seeking more reliable and fair interest relationship and reasonable distribution, Encourage the main body to work hard for the quality and safety of dairy products

To define the scope and subject of this document, the following assumptions exist in the FIMS:

Hypothesis 1: This paper only considers the secondary distribution chain composed of dairy producers and raw milk processors. Dairy farmers produce CRU milk, and processors inspect, process and sell milk products;

Hypothesis 2: only qualified and unqualified dairy products are considered, not quality;

Hypothesis 3: milk producers and processors are risk neutral;

Hypothesis 4: there are the following research scenarios: dairy farmers provide certain quality raw materials to dairy processing enterprises, and processing enterprises test raw milk. If the raw milk is qualified, all the raw milk shall be purchased and the purchase fee shall be paid to the dairy farmers; If raw milk is not reserved, processing enterprises are likely to have inspection errors, that is, raw milk without certification is inspected as qualified and can be purchased, raw milk without supply is rejected, raw materials are randomly added and sold to consumers. Consumers can accurately identify dairy products and return claims without reservation.

Hypothesis 5: qualified raw milk processors can accurately test, but unskilled raw milk may have test errors.

Hypothesis 6: the probability of consumers claiming that raw milk is below the standard is $100 \%$;

Suppose 7 dairy products produced by dairy processors are $100 \%$ qualified.

Suppose 8 only discusses the probability case, without considering the influence of consumer demand, assuming that the order quantity $\mathrm{x}=1$;

ISSN: 0010-8189

(C) CONVERTER 2020 
The specific decision-making process is shown in Figure 2-1.

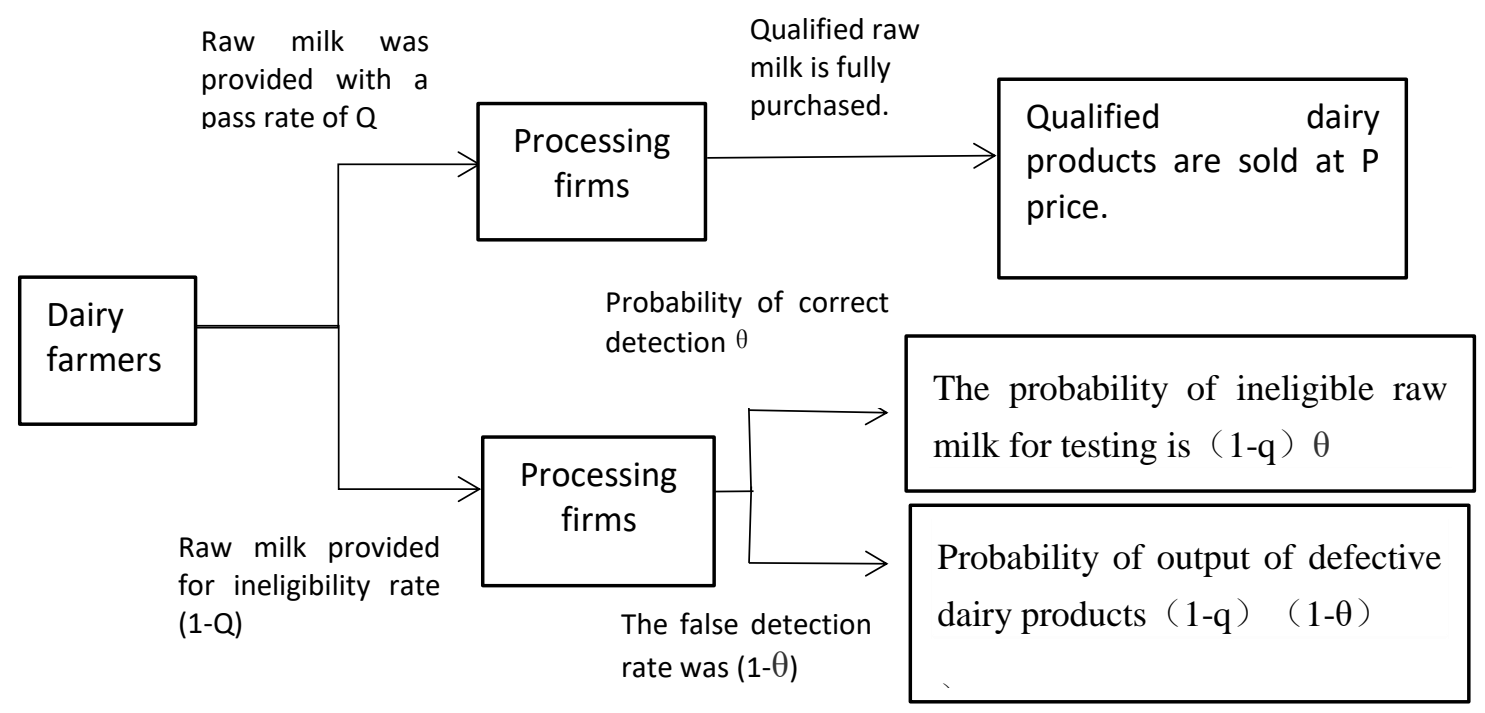

Fig 1 Decision making process of dairy production, inspection and sales

The description of the parameters is shown in table 1, which describes the main variables in detail.

(1) $Q$ is the qualified rate of raw milk of dairy farmers. This paper shows that the quality effort of dairy farmers is the highest level. The higher the qualified rate is, the higher the level of quality effort of dairy farmers is.

(2) $S(q)$ is the quality effort cost of dairy products. The performance of $S(q)$ is derived by referring to the setting of quality effort cost function in stsnley Baiman (2001).

$$
\begin{aligned}
& S(q)=\frac{1}{2} k_{1} q^{2}, k_{1}>0 \\
& S^{*}(q)>0, S^{*}(q)>0
\end{aligned}
$$

Where, $\mathrm{Ki}$ is the unit marginal effort cost coefficient of dairy farmers. According to the formula $(2-1), \mathrm{s} *(\mathrm{q})>0, \mathrm{~s} *(\mathrm{q})$ $>0$ represents the increasing marginal quality cost of dairy farmers.

(1) $\theta$ (1) As the correct inspection probability of dairy processing enterprises, this paper represents the quality effort level of dairy processing enterprises.

(2) $\beta(\theta)$ It represents the unit quality inspection cost of dairy processing enterprises, and conforms to the same cost function 2-2 as $\mathrm{s}(\mathrm{q})$.

$$
B(\theta)=\frac{1}{2} k_{2} \theta^{2}, k_{2}>0
$$

Among them, K2 is the unit marginal effort cost coefficient of dairy processing enterprises. From the formula (2), it can be concluded that, $\beta(\theta)$ Derivative $>0$ indicates that the marginal quality cost of dairy processing enterprises is ISSN: 0010-8189 
increasing.

(5) It indicates the probability of unqualified raw milk being checked out by dairy processing enterprises,

(6) $\mathrm{G}$ indicates that unqualified dairy products are sold, indicating the probability of consumer complaints.g. In addition, this combination is used to describe the quality and safety level of the final dairy products as the standard for the following analysis.

Table 3 parameter description

\begin{tabular}{l|l}
\hline parameter & Parameter description \\
\hline $\mathrm{p}$ & The level of quality efforts of dairy farmers, $0<q<1$ \\
\hline$S(q)$ & The unit quality effort cost of dairy farmers, $S(q)=\frac{1}{2} k_{1} q^{2}, k_{1}>0$ \\
\hline$\theta$ & The quality inspection level of dairy processing enterprises, $0<\theta<1$ \\
\hline$B(\theta)$ & Unit quality inspection cost of dairy processing enterprises, $B(\theta)=\frac{1}{2} k_{2} \theta^{2}, k_{2}>0$ \\
\hline$P$ & Unit price of dairy products, $P<0$ \\
\hline$c$ & Unit purchase price of raw milk, $c>0$ \\
\hline$c_{S}$ & Unit production cost of raw milk, $c_{S}>0$ \\
\hline$c_{B}$ & Unit processing cost of dairy products, $c_{B}>0$ \\
\hline$l$ & The amount of the consumer's claim, $l>0$ \\
\hline$\pi_{S i}$ & The income of dairy farmers, $\pi_{S i}>0$ \\
\hline$\pi_{B i}$ & The income of dairy processing enterprises, $\pi_{B i}>0$ \\
\hline$\pi_{R i}$ & Supply chain revenue, $\pi_{R i}>0$ \\
\hline $\mathrm{g}$ & The probability of unqualified dairy products being sold and causing consumer claims \\
\hline$\mu$ & The probability of unqualified raw milk being detected \\
\hline$u$ & The minimum retained income of dairy farmers, $u>0$ \\
\hline$\lambda_{1}$ & Proportion of quality cost subsidy to dairy farmers by dairy processing enterprises \\
\hline$\lambda_{2}$ & The proportion of loss sharing of dairy farmers to consumers \\
\hline
\end{tabular}

\section{Analysis of Optimal Benefits and Quality Safety Level under Centralized Decision Making}

This section discusses the level of production and quality safety of dairy producers and processors under completely centralized information decision-making. Under centralized decision-making, dairy producers and dairy processors have the same goal, continue to maximize the global benefits of the supply chain, and have greater advantages in quality control and cost control than decentralized decision-making ${ }^{[3]}$. This document aims at centralized decision-making and has the best quality and safety benefits and level. The supply under centralized decision is expressed in formula (3).

$$
\pi_{R i}=\left(P-c_{B}\right)[1-(1-q) \theta]-c_{S}-\mathrm{g}(1+p)-\frac{1}{2} k_{1} q^{2}-\frac{1}{2} k_{2} \theta^{2}
$$

Proposition 2-1 when the quality and safety level $\{q, \theta\}$ Meet the following conditions: $q_{1}^{*}=\frac{\left(c_{B}+l\right)^{2}-k_{2}(l+p)}{\left(c_{B}+l\right)^{2}-k_{1} k_{2}}$

$\theta_{1}^{*}=\frac{\left(c_{B}+l\right)\left(l+p-k_{1}\right)}{\left(c_{B}+l\right)^{2}-k_{1} k_{2}}$ The total revenue of supply chain under centralized decision-making is optimal.

Proof: will $\pi_{R 1}$ Respectively $\mathrm{q}$ and $\theta$ Find the first and second partial derivatives, 


$$
\begin{gathered}
\frac{\partial_{\pi_{R 1}}}{\partial_{q}}=\left(p-c_{B}\right) \theta+(l+p)(1-\theta)-k_{1} q \\
\frac{\partial^{2} \pi R_{1}}{\partial p}=-k_{1}<0 \\
\frac{\partial \pi_{R 1}}{\partial \theta}=\left(l+c_{B}\right)(1-q)-k_{2} \theta \\
\frac{\partial^{2} \pi_{R 1}}{\partial \theta}=-k_{2}<0
\end{gathered}
$$

because $\frac{\partial^{2} \pi_{R 1}}{\partial q}<0, \frac{\partial^{2} \pi_{R 1}}{\partial \theta}<0$,It is consistent with the properties of concave function when the first order partial derivative $\frac{\partial^{2} \pi_{R 1}}{\partial q}=\frac{\partial^{2} \pi_{R 1}}{\partial \theta}=0$.The results show that the supply chain system is optimal

$$
\begin{aligned}
& \frac{\partial^{2} \pi_{R 1}}{\partial q}=\left(p-c_{B}\right) \theta+(l+p)(1-\theta)-k_{1} q=0 \\
& \frac{\partial \pi_{R 1}}{\partial \theta}=\left(l+c_{B}\right)(1-q)-k_{2} \theta=0
\end{aligned}
$$

The optimal quality effort level and the optimal detection level are obtained by simultaneous equations (8) and (9)

$$
\begin{aligned}
& q_{1}^{*}=\frac{\left(l+c_{B}\right)^{2}-k_{2}(l+p)}{\left(l+c_{B}\right)^{2}-k_{1} k_{2}} \\
& \theta_{1}^{*}=\frac{\left(c_{B}+l\right)\left(l+p-k_{1}\right)}{\left(c_{B}+l\right)^{2}-k_{1} k_{2}}
\end{aligned}
$$

here $g^{*}{ }_{1}=\left(1-q^{*}{ }_{1}\right)\left(1-\theta^{*}{ }_{1}\right)$ Then the optimal quality and safety level of dairy products under centralized decision-making is $\left\{q^{*}, \theta^{*}{ }_{1}, \mathrm{~g}^{*}{ }_{1}\right\}$.By substituting formula (10) and (11) into formula (3), the most worrying profit of supply chain under the most quality and safety level can be obtained $\pi_{R 1}^{*}\left(q^{*} \theta_{1}{ }_{1}\right)$.

\section{Analysis of Optimal Profit and Quality Safety Level under Decentralized Decision}

In the context of decentralized decision-making, milk producers and milk processors are independent individuals.The performance functions of milk producers and milk processors are given in formulas (11) and (12), respectively.

$$
\begin{gathered}
\pi_{S 2}=c[1-(1-q) \theta]-c_{s}-\frac{1}{2} k_{1} q^{2} \\
\pi_{B 2}=\left(p-c-c_{B}\right)[1-(1-q) \theta]-g(1-q)-k_{2} \theta
\end{gathered}
$$

Proposition 12 when quality level $\{q, \theta\}$ Meet the following conditions: $q^{*}{ }_{2}=\frac{c\left(c_{B}+l+c\right)}{c\left(c_{B}+l+c\right)+k_{1} k_{2}}, \theta^{*}{ }_{2}=$ $\frac{k_{1}\left(c_{B}+l+c\right)}{c\left(c_{B}+l+c\right)+k_{1} k_{2}}$ Under decentralized decision-making, the income of dairy processing enterprises reached the optimal $\pi_{S 2}^{*}\left(q_{2}^{*} \theta_{2}^{*}\right)$ and $\pi^{*}{ }_{B 2}\left(q^{*}{ }_{2} \theta^{*}{ }_{2}\right)$.

prove:

ISSN: 0010-8189 
take $\pi_{S 2}$ yes $q, \pi_{B 2}$, yes $\theta$, The first and second partial derivatives are obtained respectively,

$$
\begin{gathered}
\frac{\partial \pi_{S 2}}{\partial q}=c \theta-k_{1} q \\
\frac{\partial^{2} \pi_{S 2}}{\partial q}=-k_{1} \\
\frac{\partial \pi_{B 2}}{\partial \theta}=\left(c_{B}+l+c\right)(1-q)-k_{2} \theta \\
\frac{\partial^{2} \pi_{B 2}}{\partial \theta}=-k_{2}
\end{gathered}
$$

because $\frac{\partial^{2} \pi_{S 2}}{\partial q}<, \frac{\partial^{2} \pi_{B 2}}{\partial \theta}<0, \pi_{S 2}$ and $\pi_{B 2}$ All of them conform to the properties of concave function $\frac{\partial \pi_{S 2}}{\partial q}=0$ and $\frac{\partial \pi_{B 2}}{\partial \theta}=$ 0 .At the same time, dairy farmers and dairy processing enterprises reach the optimal income respectively.

$$
\begin{gathered}
\frac{\partial \pi_{S 2}}{\partial q}=c \theta-k_{1} q=0 \\
\frac{\partial \pi_{B 2}}{\partial \theta}=\left(c_{B}+l+c\right)(1-q)-k_{2} \theta=0
\end{gathered}
$$

The results are as follows: 1

$$
\begin{aligned}
q_{2}^{*}=\frac{c\left(c_{B}+l+c\right)}{c\left(c_{B}+l+c\right)+k_{1} k_{2}} \\
\theta^{*}=\frac{k_{1}\left(c_{B}+l+c\right)}{c\left(c_{B}+l+c\right)+k_{1} k_{2}}
\end{aligned}
$$

here $g_{1}^{*}=\left(1-q^{*}{ }_{1}\right)\left(1-\theta^{*}{ }_{1}\right)$ Then the optimal quality and safety level of dairy products under decentralized decision-making is $\left\{q^{*}, \theta^{*}, \mathrm{~g}^{*}\right\}$. By substituting formulas (20) and (21) into formulas (22) and (23) respectively, the optimal income of dairy farmers and dairy processing enterprises under the optimal quality and safety level can be obtained $\pi_{S 2}^{*}\left(q_{2}^{*} \theta_{2}{ }_{2}\right)$ and $\pi_{B 2}^{*}\left(q^{*}{ }_{2} \theta_{2}{ }_{2}\right)$ The optimal revenue of the whole supply chain is $\pi^{*}{ }_{R 2}\left(q^{*}{ }_{2} \theta_{2}\right)=$ $\pi^{*}{ }_{S 2}\left(q^{*}{ }_{2} \theta_{2}^{*}\right)+\pi^{*}{ }_{B 2}\left(q^{*}{ }_{2} \theta_{2}\right)$.

\subsection{Comparison of numerical simulation between centralized decision and decentralized decision}

In this section, the numerical simulation method is used to compare and analyze the ideal quality level and ideal formula under centralized decision-making and decentralized decision-making, and the influence of variable parameters under different decisions is analyzed. The basic parameter values are shown in table $4^{[4]}$.

Table 4 parameter values

\begin{tabular}{llll}
\hline parameter & assignment & parameter & assignment \\
\hline Unit price of dairy products p & 20 & $\begin{array}{l}\text { Unit processing cost of dairy } \\
\text { products } C_{B}\end{array}$ & 2 \\
$\begin{array}{l}\text { Unit purchase price of raw } \\
\text { milk C }\end{array}$ & $\begin{array}{l}\text { Consumer claims I } \\
\text { Unit production cost of raw }\end{array}$ & & 20 \\
milk $c_{S}$ & & &
\end{tabular}

The sensitivity analysis of centralized decision-making and decentralized decision-making is made to understand the influence of parameters on each variable.

4.1.1 Sensitivity analysis under centralized decision

The parameters are substituted into the formula (4-3), (4-10), (4-11) to solve, and the variables are made by Mathematica software $\theta_{1}^{*}, \mathrm{~g}^{*}, \quad \pi^{*}{ }_{R 1}$ With parameter $k_{1}, \quad k_{2}$ And analyze the changes. 


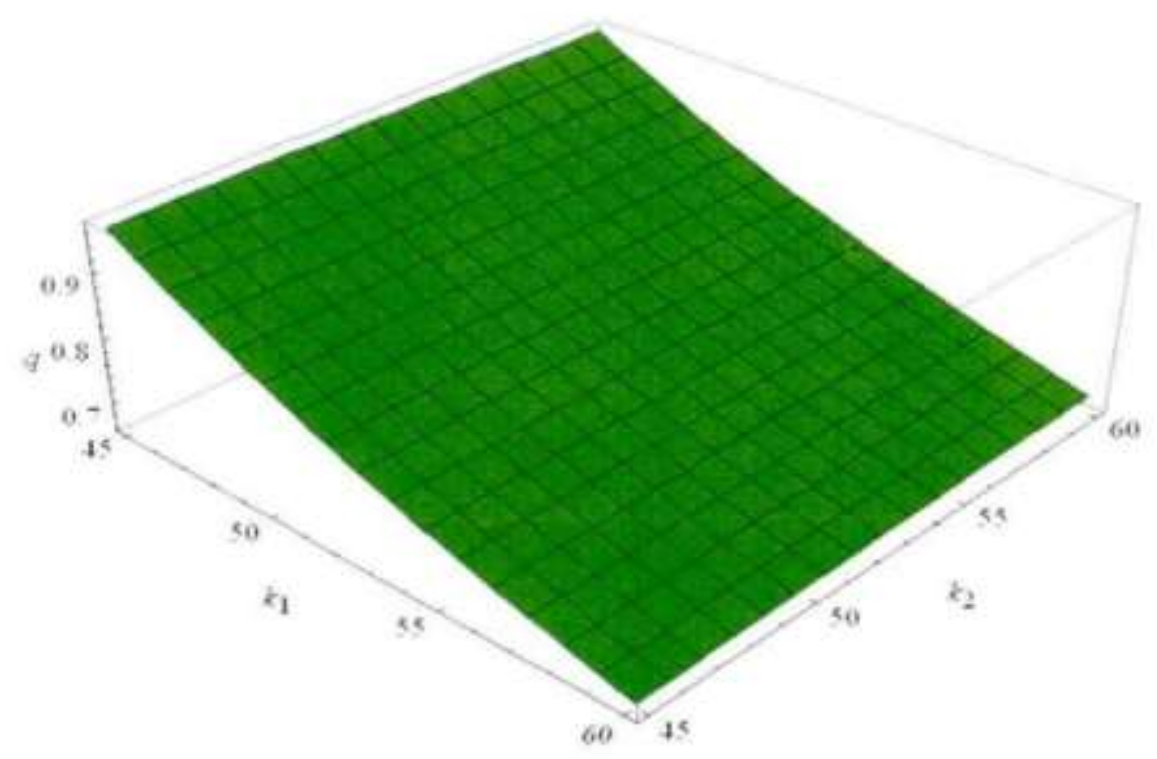

Fig 2: Changes of dairy farmers' quality effort level Q1 with K1 and K2

Figure 2 shows that the reduction of marginal quality cost of dairy producers significantly increases the quality cost of dairy producers, while the increase of marginal inspection cost of dairy farms makes the control of dairy producers more strict.In order to pass the test, the quality level of dairy farmers was slightly improved. Compared with the control group, the change of quality burden of dairy farmers was more important.

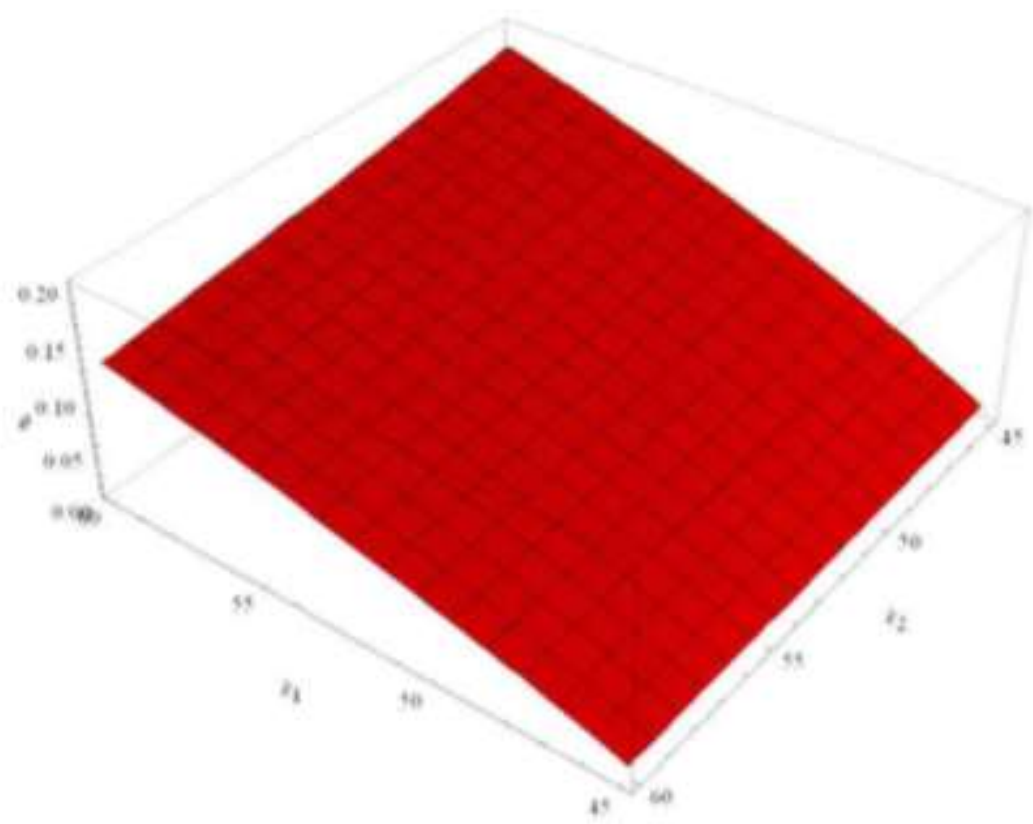

Fig 3: Changes of quality inspection level of dairy processing enterprises with, K1, K2

As shown in Figure 3, under the centralized measures, with the reduction of the limit inspection cost of the processing enterprises, the quality inspection level of the processing enterprises is improved. Combined with Figure 4-1, the quality ISSN: 0010-8189 
effort level of the dairy farmers is improved. However, the change of limit inspection cost has little effect on quality effort and inspection level.

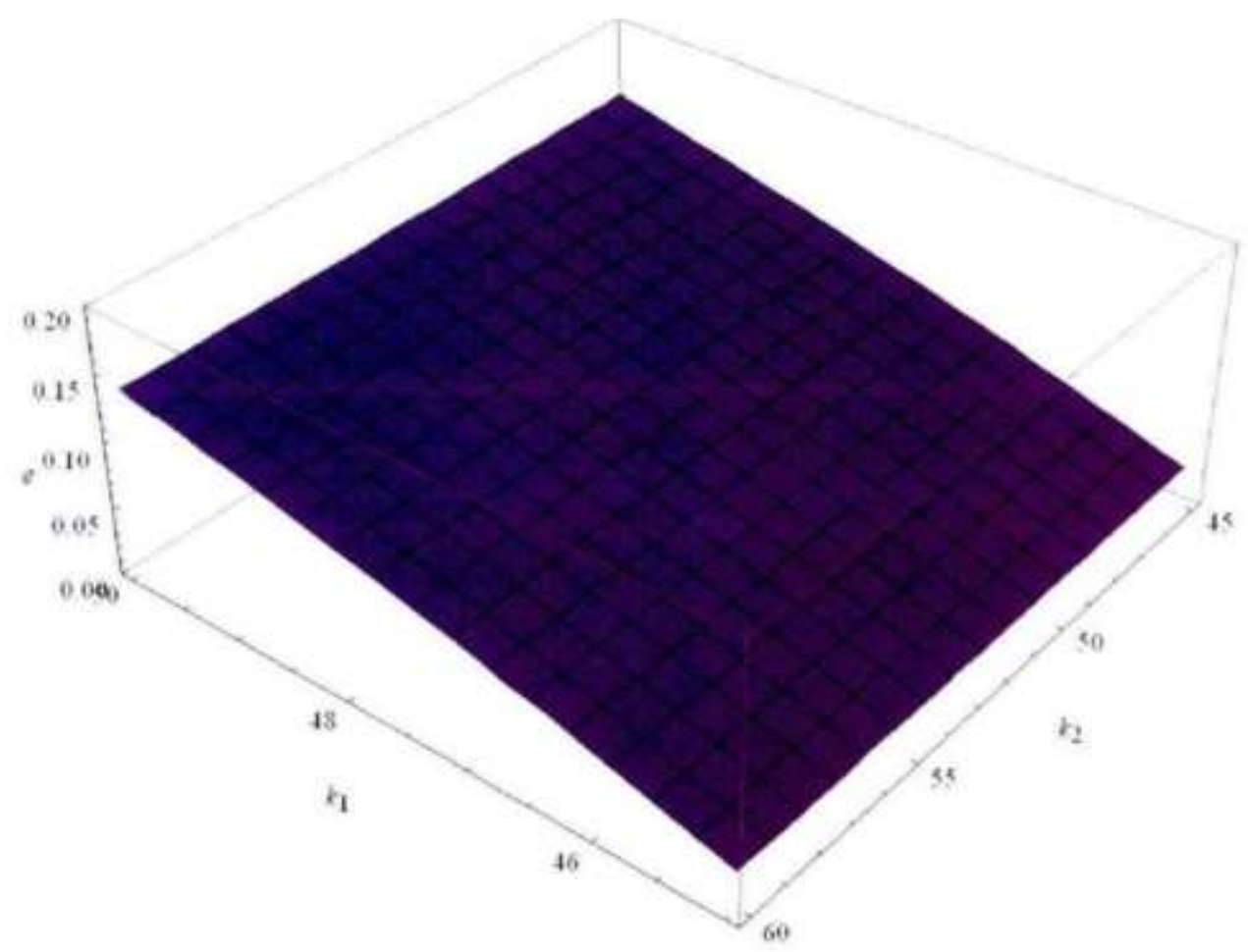

Fig 4: The change of consumer loss probability $G 1$ with K1 and K2

Figure 4 shows that with the reduction of the marginal G1 quality cost of dairy farmers and the marginal inspection costs $\mathrm{K} 1$ and $\mathrm{K} 2$ of processing enterprises, the possibility of consumer loss is reduced, which indicates that reducing the quality and safety costs helps to improve the conversion rate of dairy products. 


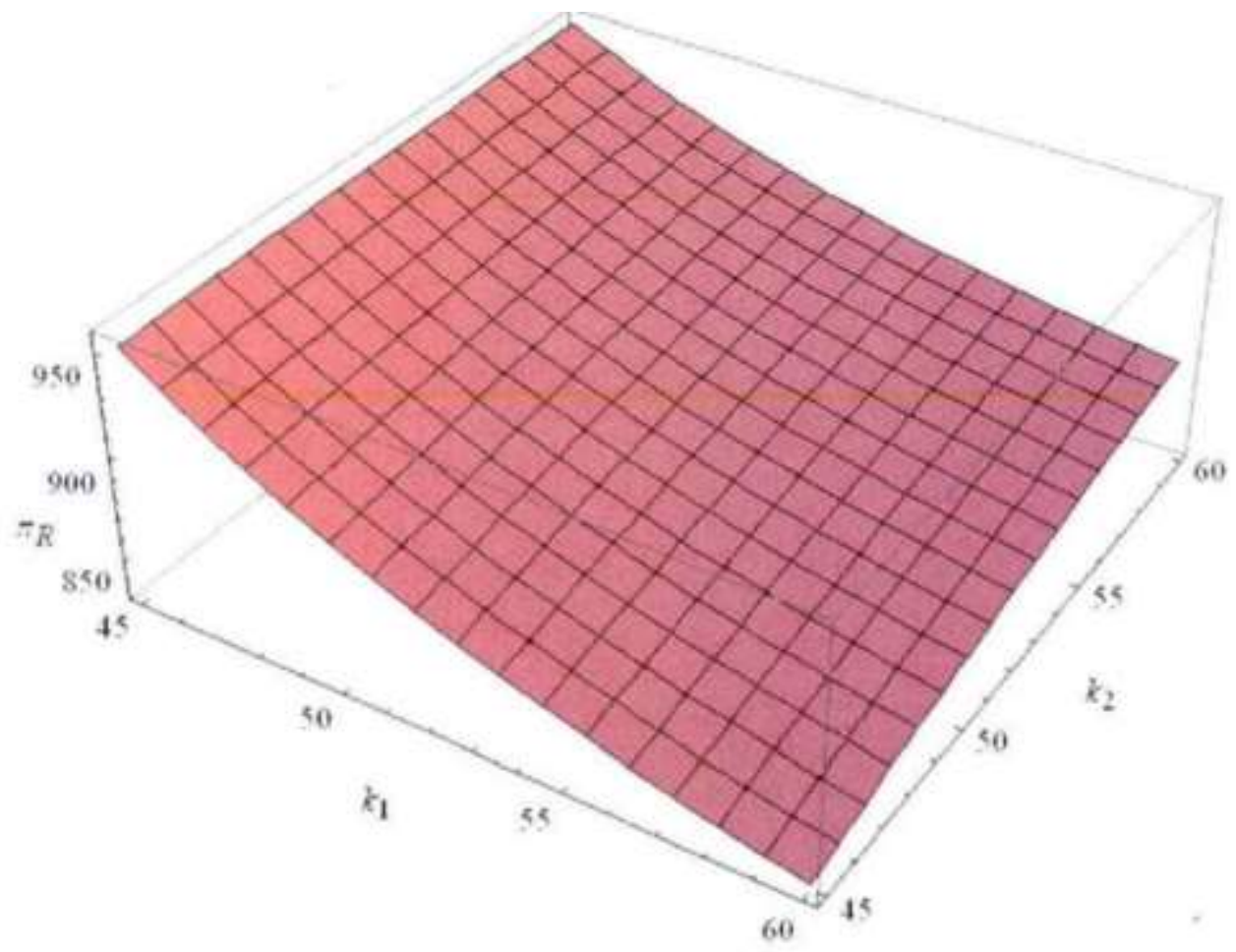

Fig 5: Total revenue of supply chain $\pi$ With the change of K1, K2R1,

Figure 5 shows that in the centralized decision-making process R1, the total revenue of the supply chain increases with the decrease of $\mathrm{K} 1$ and $\mathrm{K} 2$, and the impact on the total revenue of the supply chain is more significant.

Under the background of centralized decision-making, reducing the marginal quality cost of dairy producers and the marginal inspection cost of processors will help: in the process of centralized decision-making, dairy farmers and dairy processing enterprises are in an "integrated" state. Through internal coordination of quality burden and equivalent to a certain level of quality control, the purpose of full cooperation and optimization of the total revenue of the supply chain can be achieved ${ }^{[5]}$;

4.1.2 Sensitivity analysis of decentralized decision $\mathrm{f}$

Each parameter is substituted into the formula (4-12), (4-13), (4-14), (4-21) to solve, and the variable Q2 * is made by Mathematica software, $\theta^{*}, \mathrm{~g}^{*} 2, \pi$ The variation of $\mathrm{K} 1, \mathrm{~K} 2$ with the parameters is analyzed. ${ }_{2 \mathrm{R} 2}$ 


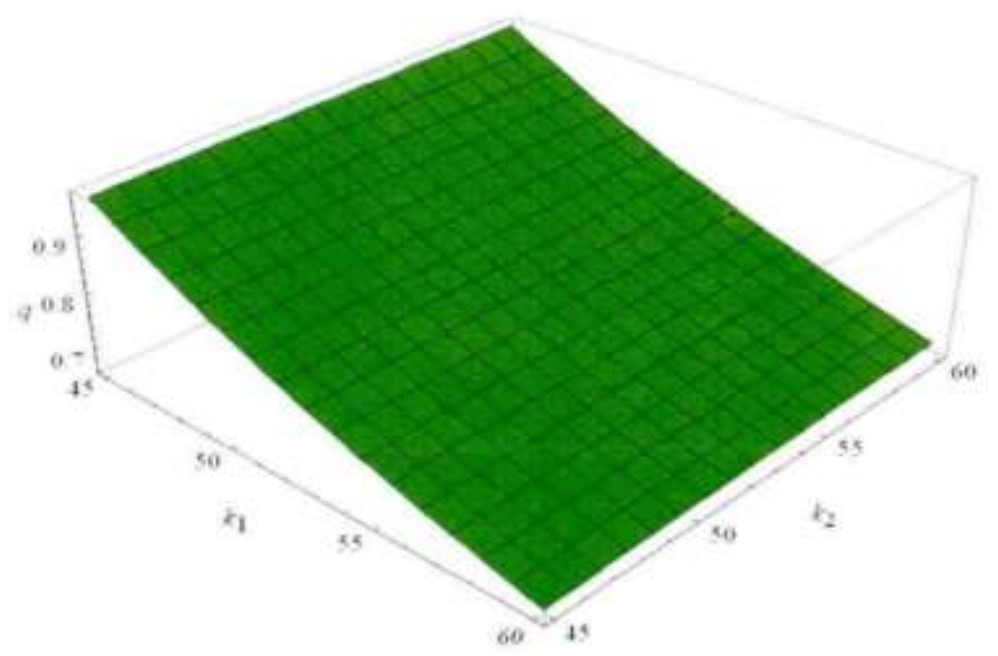

Fig 6: Changes of dairy farmers' quality effort level Q2 with K1 and K2

It can be seen from figure 6 that under decentralized decision-making, with the decrease of dairy farmers' marginal quality cost K1 and dairy processing enterprises' marginal inspection cost, the level of dairy farmers' quality effort is improved, and the impact of marginal inspection cost is more obvious. When the marginal quality cost of dairy farmers is reduced, dairy farmers have enough funds to invest in quality assurance, which improves the level of quality efforts ${ }^{[6]}$. At the same time, the reduction of marginal inspection cost of dairy processing enterprises increases the possibility of processing enterprises to invest in inspection, and the efforts of dairy farmers to pass the inspection will also increase.

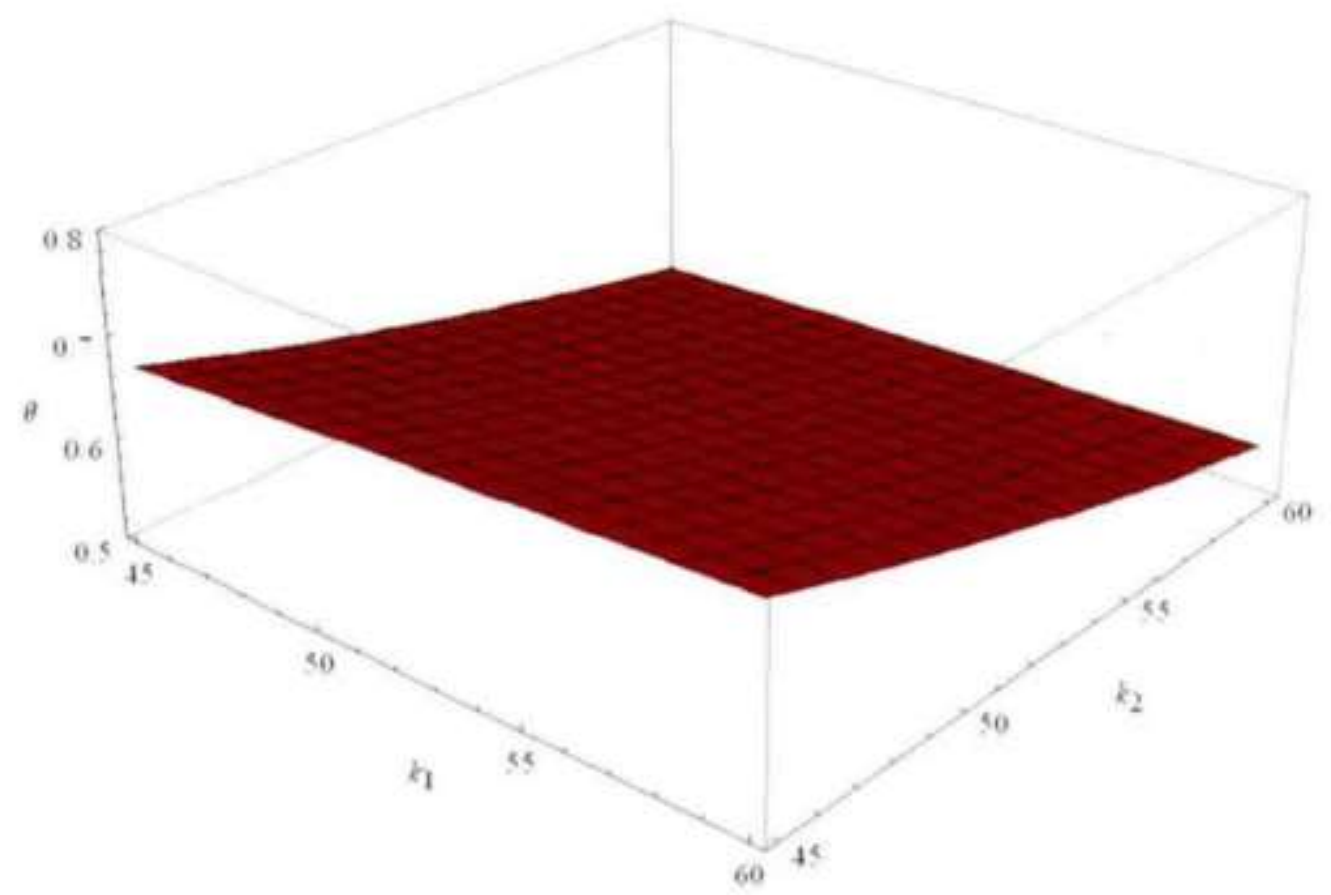

Fig 7: Quality inspection level of dairy processing enterprises $\theta$ With the change of K1, K22

As shown in Figure 7, with the decrease of the marginal inspection cost $\mathrm{K} 2$ of dairy processing enterprises under decentralized decision, the quality inspection level of processing enterprises will increase $\theta$, The change of marginal test 
cost has a significant effect on quality effort and test level.2

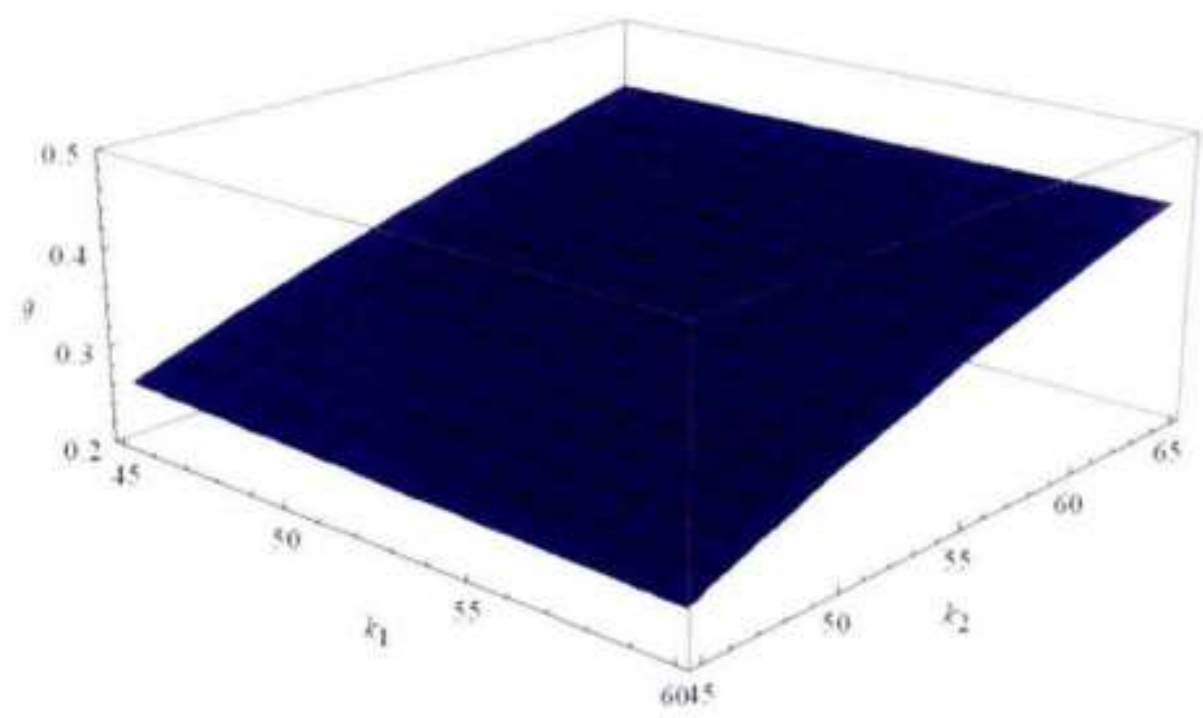

Fig 8: The probability of consumer loss $G 2$, with the change of $K 1, K 2$

Figure 8 shows that with the decrease of the marginal quality cost K1 of dairy farmers and the marginal inspection cost $\mathrm{K} 2$ of dairy processing enterprises, the probability $\mathrm{G} 2$ of consumer loss decreases, indicating that the reduction of quality and safety cost is helpful to improve the qualification rate of dairy products.G2 is greatly affected by K2.

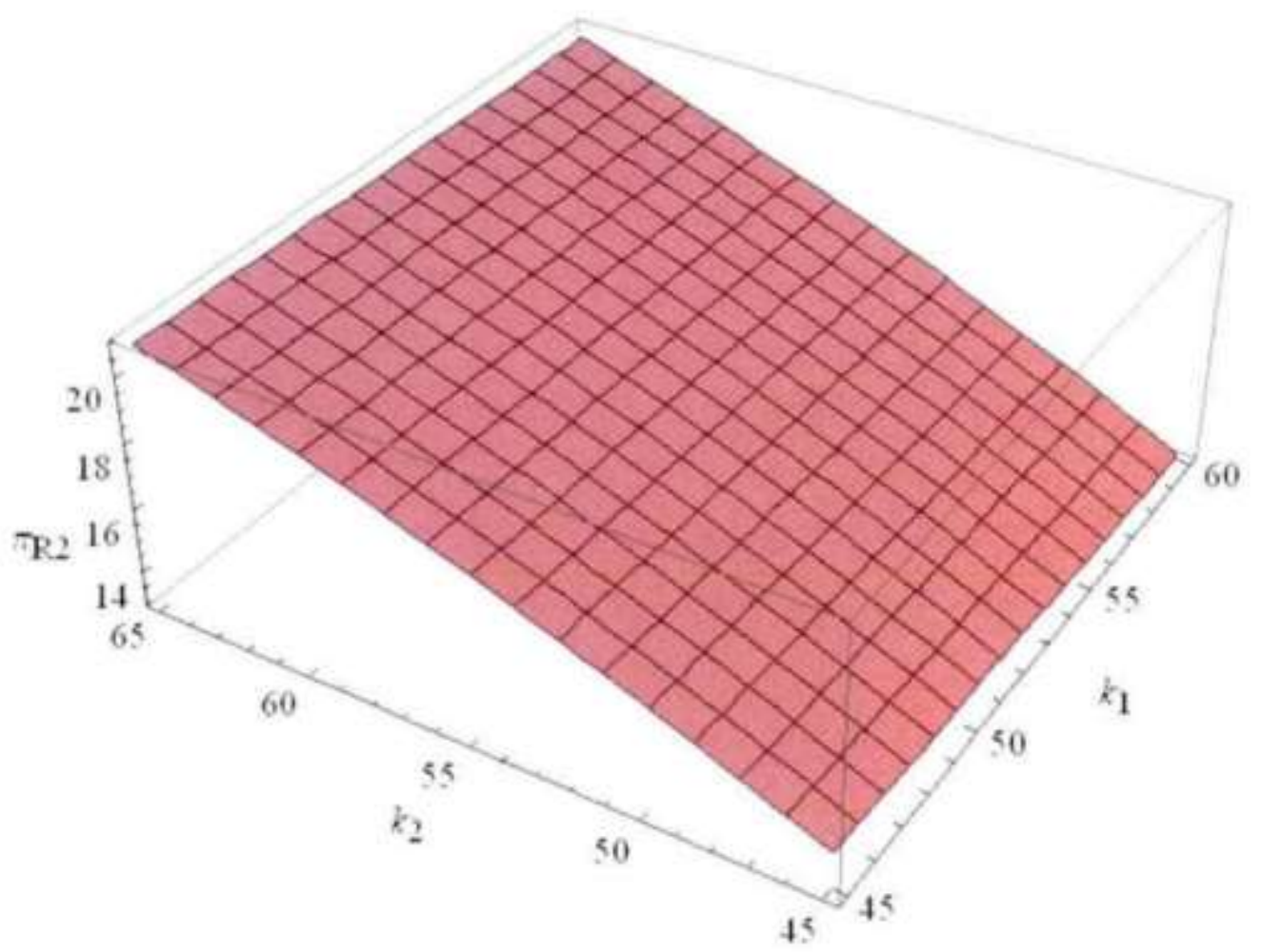

ISSN: 0010-8189 
As can be seen from figure 9, the total revenue of supply chain under decentralized decision-making $\pi$ It increases with the decrease of $\mathrm{K} 1$ and decreases with the increase of $\mathrm{K}_{2}$. The influence of $\mathrm{K}_{2}$ on the total revenue of supply chain is more significant $\mathrm{R}_{2}$,

To sum up, under decentralized decision-making, the reduction of marginal quality cost of dairy farmers and marginal inspection cost of processing enterprises are conducive to reduce the consumer losses of unqualified dairy products, and the marginal inspection cost of dairy processing enterprises has a greater impact.

In decentralized decision-making, dairy farmers provide raw milk to processing enterprises. Processing enterprises inspect raw milk, and all qualified raw milk is purchased. For unqualified raw milk, processing enterprises reject it. At this time, dairy farmers will have the loss of production $\operatorname{costs}(1-q) \theta c_{s}$ If the unqualified raw milk is processed and sold as unqualified dairy products due to inspection errors, it will lead to consumer claims and external $\operatorname{lossesg}(l+p)$.It needs to be undertaken by processing enterprises alone.

In fact, the external losses caused by consumers' claims are caused by both the unqualified raw milk provided by the dairy farmers and the wrong inspection of the processing enterprises. This part of the losses should be shared by the dairy farmers and the dairy processing enterprises, which is more fair. It is assumed that dairy farmers are pro $\operatorname{rata}_{2}(0<$ $\left.\square_{2}<1\right)$.At this time, the loss of dairy farmers isg $\left(\square_{2} l+c\right)$, Where $C$ is the return cost that dairy farmers should bear. The losses of dairy processing enterprises areg[p $\left.-\mathrm{c}-\left(1-\lambda_{2}\right) l\right]$.

The burden of external losses increases the cost pressure of dairy farmers. In order to reduce the losses, the dairy farmers' association works hard to improve the qualified rate of raw milk. According to the principle of incentive compatibility, processing enterprises need to bear part of the internal losses to avoid profits from transferring external losses. If the proportion of dairy processing enterprises $\square_{1}\left(0<\square_{1}<1\right)$ If the internal loss is shared, the internal loss to be borne by the processing enterprise is $\square_{1}(1-q) \theta c_{s}$ The internal loss of dairy farmers is $\left[1-\square_{1}(1-q) \theta\right] c_{s}$.

The purpose of this paper is to share the internal and external losses between the dairy farmers and the processing enterprises in the form of a contract, which is more decentralized decision-making $\left\{\square_{1}, \square_{2}\right\}$ Portfolio redistribution, and improve the overall quality and safety level of the supply chain.

Due to the need of this study, the following hypotheses are supplemented on the basis of hypothesis 4.1

(1) Dairy farmers and processing enterprises form cooperation under the internal and external loss sharing contract, and processing enterprises formulate the distribution coefficient of the contract $\left\{\mathrm{D}_{1}, \mathrm{Q}_{2}\right\}$ Dairy farmers choose the level of quality effort according to the distribution coefficient of processing enterprises.

(2) In order to ensure the enthusiasm of dairy farmers, the external loss of processing enterprises to the transfer of dairy farmers can not be higher than the external loss they bear, that is, the external loss of processing enterprises to the transfer of dairy farmers $\left(c+\square_{2} l-\square_{1} c_{s}\right)-(l+p)<0$.

The decision-making process of dairy farmers and dairy processing enterprises is as follows:

(1) Dairy processing enterprises provide internal and external loss sharing contract $\left\{\mathrm{Q}_{1}, \mathrm{Q}_{2}\right\}$ And select its quality inspection level $\theta$.

ISSN: 0010-8189 
(2) Dairy farmers accept or reject the contract. If they accept the contract, they choose their quality effort level q.

(3) Dairy processing enterprises purchase raw milk, and $\theta$ Test. If the inspection is qualified, all of them will be purchased. If the inspection is not up to standard, it will be returned to the dairy farmers, and according to the proportion $\mathrm{Z}_{1}$ Bear the production cost loss of dairy farmers.

(4) Dairy processing enterprises will process the raw milk which has passed the inspection and sell it at the price of P.If consumers buy substandard dairy products, there will be consumer losses $(l+p)$.

(5) According to the contract, the dairy farmers compensate the dairy processing enterprises $\left(c+\square_{2} l\right)$ The loss of money. Under the internal and external loss sub contract, the income functions of dairy farmers, processing enterprises and supply chain are shown in formulas (4-12) and (4-13).

$$
\begin{gathered}
\pi_{S 3}=c[1-(1-q) \theta]-\left[1-\square_{1}(1-q) \theta\right] c_{s}-\left(c+\square_{2} l\right) g-\frac{1}{2} k_{1} q^{2} \\
\pi_{B 3}=\left(p-c-c_{B}\right)[1-(1-q) \theta]-e(l+p)-\square_{1}(1-q) \theta c_{s}+\left(c+\square_{2} l\right) g-\frac{1}{2} k_{2} \theta^{2} \\
\pi_{R 3}=\left(p-c_{B}\right)[1-(1-q) \theta]-c_{s}-g(l+p)-\frac{1}{2} k_{1} q^{2}-\frac{1}{2} k_{2} \theta^{2}
\end{gathered}
$$

In this contract, dairy processing enterprises are at the core of the contract, which is to ensure that dairy farmers get the minimum retained income $u(u>0)$ In order to maximize their own interests, processing enterprises should choose the optimal quality inspection level.

When the supply chain obtains the best quality and safety level and the dairy processing enterprise obtains the maximum profit, the dairy farmers can obtain the minimum retained income. Take the equal sign of formula (22) to substitute formula (23), establish the simultaneous formula (24), and require.

$$
\begin{gathered}
\frac{\partial \pi_{S 3}}{\partial q}=0 \\
\square_{1}=\frac{2\left(u+k_{1} q_{3}-c\right)+4 c_{S}\left(1-q_{3}\right) \theta^{*}{ }_{3}-k_{1} q_{3}{ }^{2}}{4 c_{S}\left(1-q_{3}\right) \theta_{3}} \\
\square_{2}=\frac{2\left(k_{1} q_{3}-c-u\right)+4 c q_{3}-3 k_{1} q_{3}{ }^{2}}{4 l\left(1-q_{3}\right)\left(1-\theta_{3}\right)}
\end{gathered}
$$

4.3An analysis of the validity of contract

Under this contract, if we can achieve the same level of effort as centralized decision-making, that contract is valid.To prove the validity of the contract.

By substituting the equal sign of formula (23) into formula (24) and simultaneous formulas (26) and (27), the optimal quality and safety level of supply chain can be obtained as follows $\left\{q^{*}{ }_{3}, \theta^{*}{ }_{3}, \mathrm{~g}_{3}{ }_{3}\right\}$.The following numerical analysis shows that the distribution method is effective to improve the quality and safety of dairy products. $\operatorname{order}_{S 3}(q, \theta)=u$.To construct the Grange function of the formula, enter the following:

$$
\mathrm{L}=\pi_{B 3}+\mathrm{D}\left(\pi_{S 3}-u\right)+\delta \frac{\partial \pi_{S 3}}{\partial q}
$$

When dairy farmers and dairy processing enterprises choose the best quality effort level and quality inspection ISSN: 0010-8189 
level, $\square_{1}$ and $\square_{2}$. The change of income will not cause the change of both sides' income, there is a problem $\frac{\partial L}{\partial \square_{1}}=$ 0and $\frac{\partial L}{\partial \mathrm{D}_{2}}=0$

$$
\begin{aligned}
\frac{\partial L}{\partial \square_{1}} & =(\square-1)(1-q) \theta c_{s}-\partial \theta c_{s}=0 \\
\frac{\partial L}{\partial \square_{2}} & =(\square-1)(1-q)(1-\theta) l+\delta l(1-\theta)=0
\end{aligned}
$$

The simultaneous formula can be obtained as follows $\square=1, \delta=0$. We substitute it into the formula to make the $\frac{\partial L}{\partial q}=$ 0and $\frac{\partial L}{\partial \theta}=0$. It can be obtained that:

$$
\begin{gathered}
\frac{\partial L}{\partial q}=\left(p-c_{B}\right) \theta+(l+p)(1-\theta)-k_{1} q=0 \\
\frac{\partial L}{\partial \theta}=\left(l+c_{B}\right)(1-q)-k_{2} \theta=0
\end{gathered}
$$

Compared with the form of centralized decision-making, there are some problems $q^{*}{ }_{3}=q^{*}{ }_{1}, \theta^{*}{ }_{3}=\theta^{*}{ }_{1}$, That is to say, the supply chain under the above internal and external loss sharing contract can achieve the same quality level as that under the centralized decision.

\subsection{Numerical analysis}

This part uses the numerical analysis method to analyze how the income of dairy farmers and dairy processors changes and whether the quality level is improved after the contract coordination.

First of all, when the contract is coordinated, the total revenue of the supply chain will change the contract coefficient. The total revenue of the supply chain is equal to the total revenue of the supply chain under the centralized decision-making. In this case, it does not affect the total revenue of the supply chain ${ }^{[7]}$. It shows that the dairy processing enterprises and farmers are integrated at this time, and there is no internal loss sharing, The total revenue of supply chain is equal to the total revenue of supply chain under centralized decision. The total revenue of supply chain changes with contract coefficient after contract coordination $\lambda 2$, as shown in Figure 10, the total revenue of supply chain after contract coordination is always greater than the total revenue under decentralized decision-making, and no matter What is the value $\lambda_{2}=1$ the total revenue of supply chain is equal to the revenue of supply chain under centralized decision. In this case $\lambda$ It does not affect the total revenue of the supply chain, which indicates that dairy processing enterprises and farmers are integrated at this time, and there is no internal loss sharing $\lambda_{2}=1$, the total revenue of supply chain is equal to the revenue of supply chain under centralized decision. 


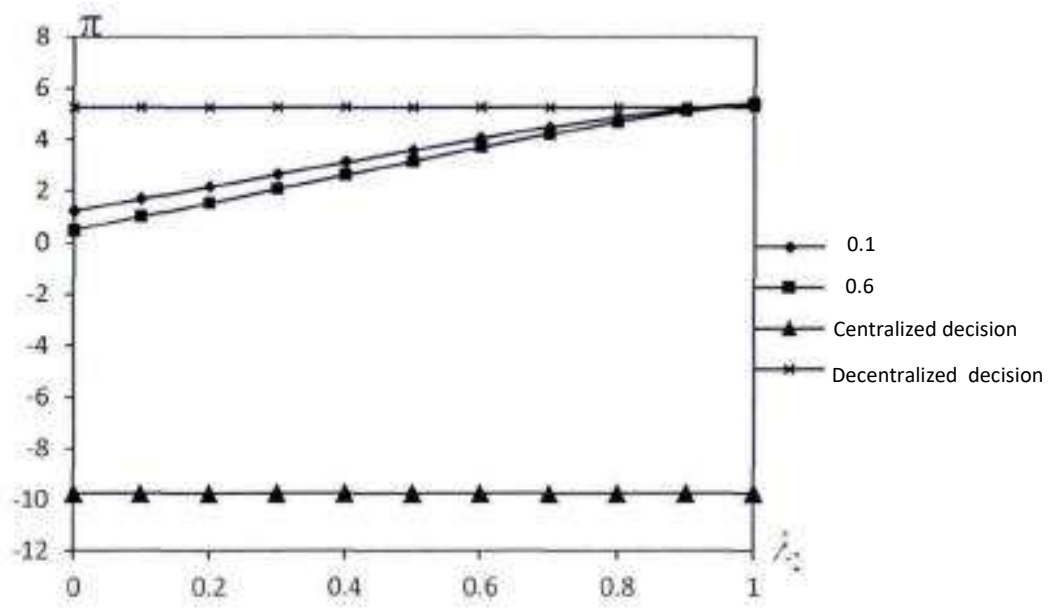

Fig 10: Changes of total benefits of supply chain after contract coordination

Secondly, the paper analyzes the effect of contract coordination on the income of dairy farmers and processing enterprises $\lambda_{2}$, and compared with the income of dairy farmers and processing enterprises under decentralized decision-making, as shown in Figure 11.

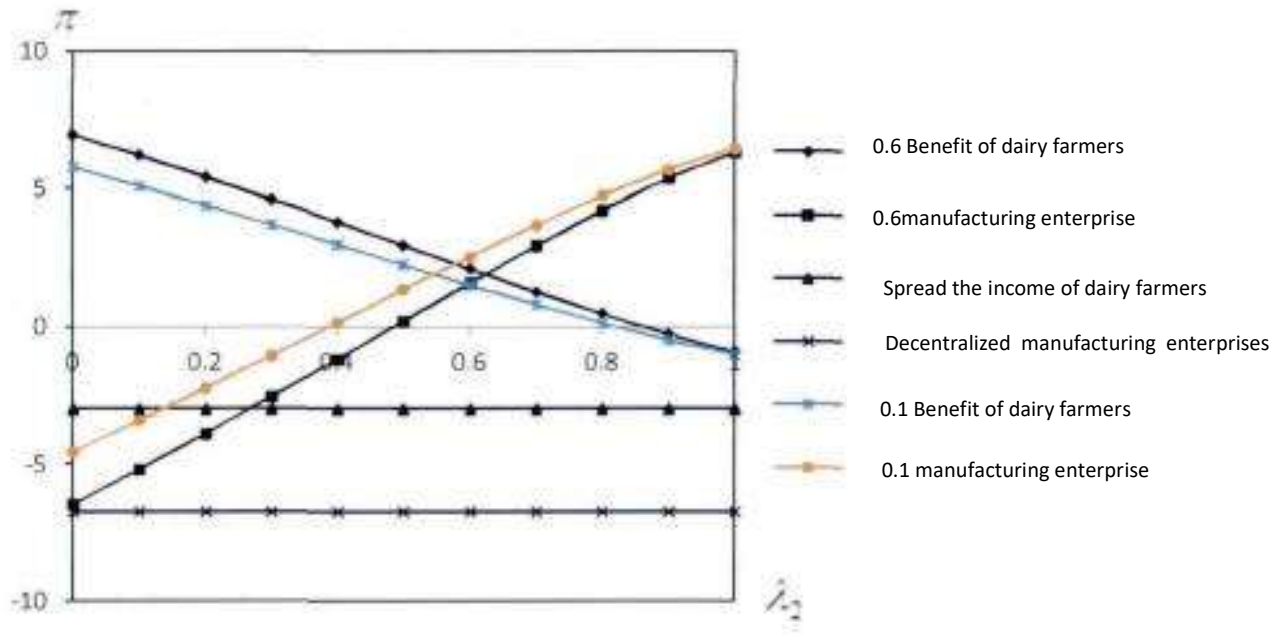

Fig 11: Comparison of income contract between dairy farmers and dairy processing enterprises

Under the coordination of internal and external loss sharing contract, the income of dairy farmers and dairy farmers is higher than that of decentralized decision-making. When the internal component coefficient is constant, under certain conditions, the income of dairy producers will increase with the increase of income ${ }^{[8]}$. It is in line with the principle of fairness to reduce the cost of dairy farmers and increase their income. In order not to harm their own interests, dairy farmers and dairy processors must negotiate well $\left\{\mathrm{D}_{1}, \mathrm{D}_{2}\right\}$ Value range of.

Then, analysis order $\square_{1}=0.6 \mathrm{and}_{2}=0.1$, After the contract coordination, the quality effort level of dairy farmers increases with the contract coefficient $\lambda 2$, as shown in Figure 12.

Then, analysis order $\square_{1}=0.6 \mathrm{and} \square_{2}=0.1$, After the contract coordination, the quality effort level of dairy farmers increases with the contract coefficient $\mathrm{D}_{2}$ Figure 12 shows the trend of the change.

ISSN: 0010-8189 


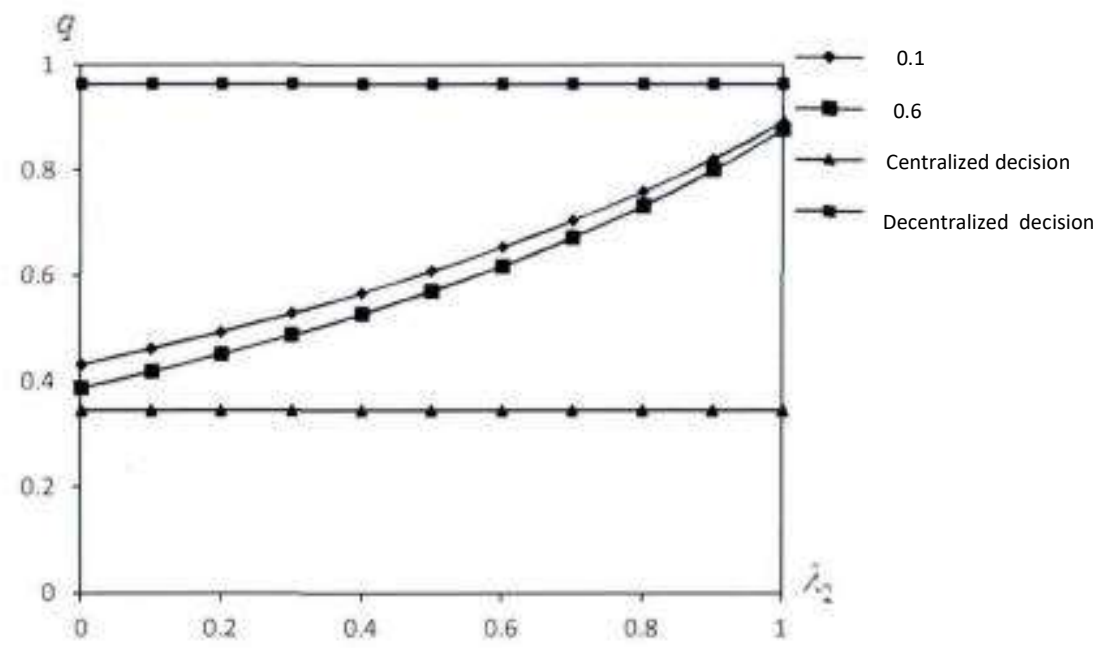

Fig 12: Comparison of quality efforts of dairy farmers before and after contract coordination

It can be seen from figure 12 that the quality effort level of milk producers after contract coordination is higher than that of decentralized decision-making, and with the increase of contract coordination, the quality effort level of dairy producers is higher than that of decentralized decision-making. When dairy producers share a high proportion of consumer losses, dairy producers will make more efforts to ensure quality and safety and avoid the end of losses. When the dairy processing enterprises subsidize the dairy production enterprises, and the internal loss is large, the dairy production enterprises will no longer have higher cost pressure, and will produce dependence psychology and reduce the level of quality efforts. Therefore, we should not only rationally distribute the interests of all parties, but also maintain the enthusiasm of both sides to improve the quality and cooperation.

Then, the relationship between the loss probability and the contract coefficient is analyzed $\mathrm{D}_{2}$, as shown in Figure 13 .

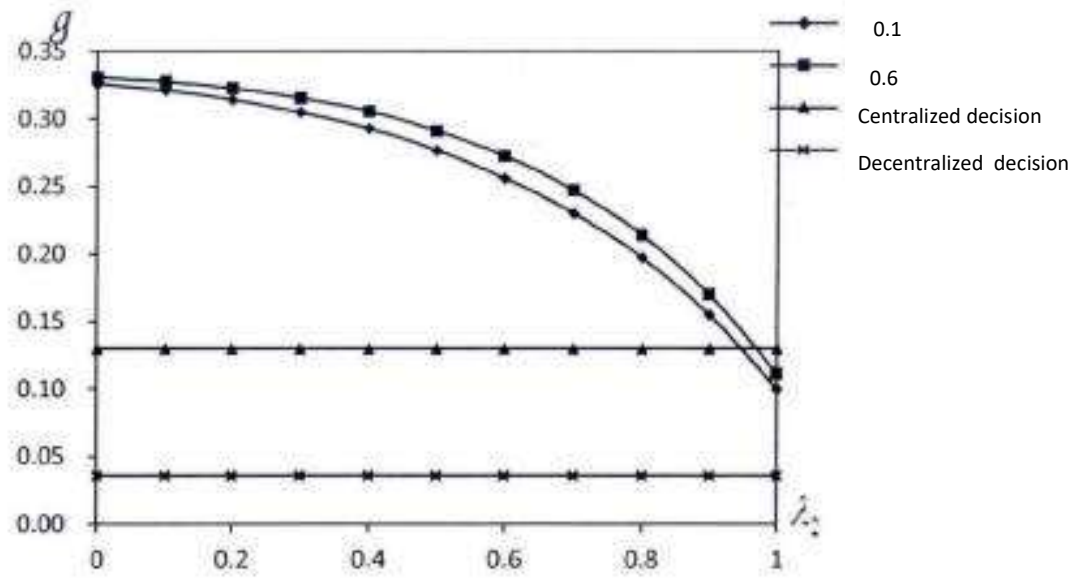

Fig 13: Distribution coefficient of probability g of consumer loss 2 Changes

As can be seen from figure13, under the internal and external loss sharing contract, with the increase of the contract coefficient. With the increase of 2 , the probability of consumer loss decreases gradually $\lambda$ When 2 approaches to 1 , the probability of consumer loss is lower than that under decentralized decision-making, which indicates that in order to ensure consumer safety, dairy farmers, as the source of dairy quality and safety control, need to bear more external losses,

ISSN: 0010-8189 
which also proves that raw milk is an important link to ensure the quality and safety of dairy products.

\section{Conclusion}

This paper discusses the optimal quality and safety level and optimal revenue of the two-level dairy supply chain based on the pass rate of dairy farmers and dairy processing enterprises under decentralized and centralized decision-making. In order to improve the level of quality efforts of dairy farmers, an internal and external loss sharing contract is designed, that is, dairy farmers and dairy processing enterprises share consumer losses At the same time, processing enterprises provide certain quality cost subsidies for dairy farmers. Finally, through the example analysis, it is verified that the benefit sharing and risk sharing between dairy farmers and Guopin processing enterprises can be realized through the contract. After the contract coordination, the benefits allocated by dairy farmers and processing enterprises and the quality and safety level of supply chain are optimized, and the importance of quality control in raw milk production is further verified.

\section{Acknowledgements}

National Natural fund of China (71673042, 71640017);Cultural celebrities and "four one batch" talent optional project of the Propaganda Department of the CPC Central Committee (201801);Research and planning project of philosophy and Social Sciences in Heilongjiang Province (18JYC257).

\section{Reference}

[1] Y.F. Wang, R.H. Xie. "Supply chain management. Logistics technology," vol. 9, no. 2, pp. 32-36, 2007.

[2] Y.L Wu. "Review and Prospect of agricultural product supply chain management at home and abroad," China business, vol.4, no.8, pp, 137-139, 2015.

[3] H. Dormnom, "Guide to good dairy farming practice. Fao Animal Production \&Health Guidelines," vol. 6, no.10, pp. 9-15, 2004.

[4] P.D.J.M. G. Lankveld "Quality, safety and value optimisation of the milk supply chain in rapidity evolving," Central and Easterm European markets (OPTIMILK). vol.5, no. 9, pp. 2-7, 2004.

[5] G, Faye B., G. Loiseau G, D. Levieux. (2006). "Lactoferrin and Immunoglobin content in camel milk from Kazakhstan. J. Dairy Sci. vol. 9, no. 2, pp. 11-14, 2020.

[6] W. M Yang, D.H Hu. "Research on the innovation of dairy industry chain and organization mode under the background of food safety," Journal of Inner Mongolia University (Philosophy And Social Sciences Edition), vol. 11,no. 6, pp. 32-37, 2010.

[7] S.X Hou, M Zhong. research on the relationship between dairy processing enterprises and dairy farmers from the perspective of industrial chain. Economic Forum, vol. 08,no. 2, pp. 141-144, 2010.

[8] B. Pan. "Research on the vertical organization relationship of dairy industry chain in the Netherlands -- Based on the perspective of interest correlation," Science and management, vol. 29 no. 2, pp. 71-73, 2009. 